\title{
Adverse Risk Interaction: An Integrated Approach
}

\author{
Jelena Ivanović ${ }^{1}$ and Miloš Božović ${ }^{2}$
}

This draft: May 4, 2014

\begin{abstract}
This paper seeks to identify and quantify adverse interaction between credit and market risk. We develop a comprehensive Merton-type model, in which payment ability of borrowers is driven by the overall economic growth, while the level of their liabilities is sensitive to market variables. To illustrate the model, we use industry-wide data from the Serbian banking sector where euroization is predominant and post-crisis corporate defaults are significant. We apply numerical simulations to estimate pure-credit, pure-market and integrated Value at Risk from the loss distribution, and show that the adverse interaction between credit and market risk amounts to approximately 2.5 percent of the combined credit portfolio of all the banks. Even after accounting for the presence of market risk in the banking book, the total risk remains higher than the sum of credit and market risk, indicating the importance of integrated approach to assessment of economic capital.
\end{abstract}

Keywords: risk interaction; integrated market and credit risk assessment; banking book; economic capital; macroeconomic stress tests

EFM Classification Codes: 450, 520, 620

\footnotetext{
${ }^{1}$ Center for Investments and Finance, Belgrade, Serbia; corresponding author; email: jelena.ivanovicecif.co.rs

${ }^{2}$ Faculty of Economics, University of Belgrade, Serbia
} 


\section{Introduction}

Banking regulators have traditionally thought of credit risk as mainly relevant for the banking book and market risk as mainly relevant for the trading book. This view is reflected in Basel regulatory framework, which makes a clear distinction between capital requirements for credit and market risk. The minimum capital requirement under Pillar 1 of Basel II and III is obtained as a sum of minimum requirements for credit, market and operational risk (see, for instance, Basel Committee on Banking Supervision, 2006 and 2010). Capital rules thus do not allow for risk diversification effects, but neither do they encompass potential negative interactions of risks. The importance of negative interplay between credit and market risk is recognised under Pillar 2, which requires banks to estimate their own set-aside capital. Under internal capital adequacy assessment process (ICAAP), banks are obliged to assess required capital across all sources of risk that are not taken into account under Pillar 1. Additional credit risk, caused by market factors that typically affect trading book - such as exchange rates and interest rates, is a typical source of risk that should be addressed under Pillar 2.

There are two broad groups of papers that analyse the nature of the interaction between risks in the banking book. The first group argues that simple aggregation of risk measures across different risk types ignores potential diversification benefits, thereby leading to overestimation of risk and redundant capital charges. Alessandri and Drehmann (2009) derive an economic capital model which measures credit and interest-rate risk in the banking book in an integrated fashion. They find the integrated economic capital and compare it to the simple sum of economic capitals for credit and interest-rate risk.

Their analysis shows that the simple sum exceeds integrated capital under a broad range of circumstances. The authors provide the intuition for their result by arguing that relatively large portion of credit risk is idiosyncratic, and therefore independent of the macroeconomic environment.

The second group consists of authors who argue that not only there is no diversification between credit and market risk, but the evidence can be found that there is in fact "negative diversification". This adverse risk interaction would mean that the overall risk is actually higher than the simple sum of its stand-alone components. Therefore, a bottom-up approach, in which capital charges for credit and market risk are separately estimated and then simply added up, can lead to substantial underestimation of capital required to absorb unexpected losses. Breuer et al. (2010) challenge the traditional view that integrated risk capital will always be smaller than the sum of market and credit risk capital. Using a 
simple model and its real-world extension, they show that under the traditional regulatory approach the true risk of a portfolio of foreign currency loans would be significantly underestimated. Their analysis shows that a simple addition of separately measured foreign-exchange and default risk underestimates the actual level of risk several times. For instance, for a $\mathrm{B}+$ rated obligor the integrated risk measurement approach leads to an overall risk that is 1.5 to 7.5 times larger than the one derived when each component is measured separately and then added up. This effect becomes even more pronounced for portfolios with lower ratings.

Božović et al. (2009) analyse the spillover of the exchange-rate risk of foreign currency loans into default risk. They show that in an economy where foreign currency loans are a dominant source of economic growth financing, depreciation of the local currency establishes a negative feedback loop in which local currency depreciation leads to higher default probabilities, credit crunch, and reduced growth. The authors model the interaction of foreign exchange risk and credit risk in a partial equilibrium setup with rational expectations. The spillover works in the following fashion. The exchange-rate risk increases the default risk of an unhedged foreign currency borrower, whose revenues are in local currency, as the depreciation inflates the value of her liabilities in local currency. Higher default risk implies tightening of credit conditions, e.g. higher interest rates and generally, lower credit supply. This credit contraction leads to a negative effect on future growth, which in turn reduces the credit demand today through rational expectations of borrowers. As a result, the equilibrium supply of credit will be further reduced, which creates a negative feedback loop, bringing the economy in an equilibrium in which the growth may slow down or decrease substantially.

Drehmann et al. (2008) derive a general framework for measuring the integrated impact of credit and interest-rate risk on bank portfolios. They apply the framework to a hypothetical bank in normal and stressed conditions and show that it is essential to measure the impact of interest-rate and credit risk jointly. Böcker and Hillebrand (2009) investigate the interaction between risk of credit portfolio and market risk. They combine Merton-like factor models for credit risk with linear factor models for market risk and analytically calculate their inter-risk correlation. Taking a practitioner's perspective, they show how inter-risk correlation bounds can be derived. Chan-Lau and Santos (2006) take the perspective of a borrower and propose several structural models for measuring default risk for firms with currency mismatches in their asset/liability structure. Their paper offers two wider model applications: the measurement of systematic risk in the corporate sector and the estimation of 
prudential leverage ratios in firms' balance sheets consistent with regulatory capital ratios in the banking sector.

This paper seeks to identify the specific linkage between adverse movements of exchange rate and interest rates on one hand, and credit risk on the other hand. Its major contribution is identification and quantification of the adverse interaction between market and credit risk. Moreover, we propose a framework for assessing integrated Value at Risk (VaR) in the banking book. Additionally, since the dynamics of market variables in the model is derived from macroeconomic fundamentals (GDP and inflation), the framework can be easily extended to incorporate macroeconomic stress tests. Commercial banks can use the model as an integral part of ICAAP, but on equal footing it can be used by regulators as a part of supervisory review and evaluation process (SREP). We illustrate the model on the example of industry-wide data from the Serbian banking sector. High level of euroization of the banking book makes Serbian banks very suitable for practical application of the model. However, the proposed framework can be universally applied to any financial sector in an economy in which substantial borrowing occurs in a single foreign currency.

The remainder of the paper is structured as follows: Section 2 develops a model of spillover of exchange rate and interest rate movements, which are driven by the macroeconomic fundamentals, into credit risk. Section 3 provides an empirical illustration of the model. Results of the Monte Carlo simulation confirm the existence of adverse risk interaction, which is quantified in Section 4 as additional VaR above the sum of pure-credit and pure-market risk VaR. Section 5 discusses possible applications of our results in risk management and banking supervision, and shows how the framework can be extended to design of macroeconomic stress tests. Section 6 concludes.

\section{The Model}

We model the adverse interaction of market and credit risk using a Merton-like setting. The key variables in our model are the level of borrower's liabilities at time $t$, denoted by $L_{t}$, and her payment ability at time $t$, denoted by $P A_{t}$. When the loan is originated, payment ability is above the level of liabilities, i.e. $P A_{0}>L_{0}$. As in Merton (1974), if payment ability is higher than the level of liabilities at maturity of the loan, borrower will pay back the loan in full. Otherwise, she will only pay up to the level of her payment ability. The loss incurred by the lender is therefore: 
loss $_{t}=\max \left\{L_{t}-P A_{t}, 0\right\}$

Following Breuer et al. (2010), we assume that on average the payment ability of each borrower, expressed in borrower's local currency, grows at the same rate as GDP:

$\ln \left(\frac{P A_{t}}{P A_{0}}\right)=\ln \left(\frac{Y_{t}}{Y_{0}}\right)+\varepsilon_{t}$

Here, $Y_{t}$ is GDP level at time $t$, whereas $\varepsilon_{t} \sim N(0,1)$ is an idiosyncratic random component. The intuition behind equation (2) is that the borrower's overall payment ability will, on average, follow the economic cycle. Therefore, the capacity of borrowers to meet their liabilities will, on average, be higher during periods of economic growth and lower during periods of economic downturn. Realisations of error term $\varepsilon_{t}$ are independent across different borrowers and capture any borrowerspecific credit events that may occur during the life of the loan.

On the other hand, we assume the level of liabilities $L_{t}$ expressed in borrower's local currency changes under the influence of three market variables: exchange rate with respect to the currency of denomination of the loan (or "foreign currency"), short-term interest rate on local currency, and shortterm interest rate on foreign currency. Any appreciation of the foreign currency will inflate the value of liabilities expressed in the local currency. For simplicity, we will assume that the borrowers are not hedged against exchange-rate risk, so there will be no corresponding increase in their payment ability. An increase in interest rates works in a similar fashion - the first-order effect is that it inflates any interest-bearing liabilities. The total value of liabilities at time $t$, in local currency, will be given by:

$$
L_{t}=L_{\text {interes }, 0}^{f c} \frac{X_{t}}{X_{0}} \frac{i_{t}^{f c}}{i_{0}^{f c}}+L_{\text {principal }, 0}^{f c} \frac{X_{t}}{X_{0}}+L_{\text {interest }, 0}^{l c} \frac{i_{t}^{l c}}{i_{0}^{l c}}+L_{\text {principal }, 0}^{l c}
$$

In equation (3), $L_{\text {interest }, 0}^{f c}$ and $L_{\text {principal }, 0}^{f c}$ are, respectively, the initial values of interest and principal payments related to foreign-currency loans; similarly, $L^{l c}{ }_{\text {interest }, O} O$ and $L^{l c}{ }_{\text {principal }, O}$ are the initial values of interest and principal payments related to local-currency loans; $X_{t}$ is the exchange rate at time $t$, whereas $i^{f c}$ and $i^{l c}$ are short-term interest rates on foreign and local currency, respectively.

There are four fundamental macroeconomic variables driving the dynamics of both borrowers' payment ability their liabilities. These are inflation rate and GDP pairs related to the local and the "foreign" economy. We assume that these macroeconomic fundamentals are exogenous and model 
them by four auxiliary processes. The auxiliary processes feed into the model as follows. First, domestic GDP drives the dynamics of $P A$, as in equation (2). Second, GDP and inflation of both economies feed into their respective interest rates through Taylor rules. Third, the interest rates determine the exchange rate through risk-adjusted expectations, following the uncovered interest-rate parity. The relationships captured by the model are illustrated in Figure 1.

Figure 1. Transmission mechanism of macroeconomic fundamentals into default risk

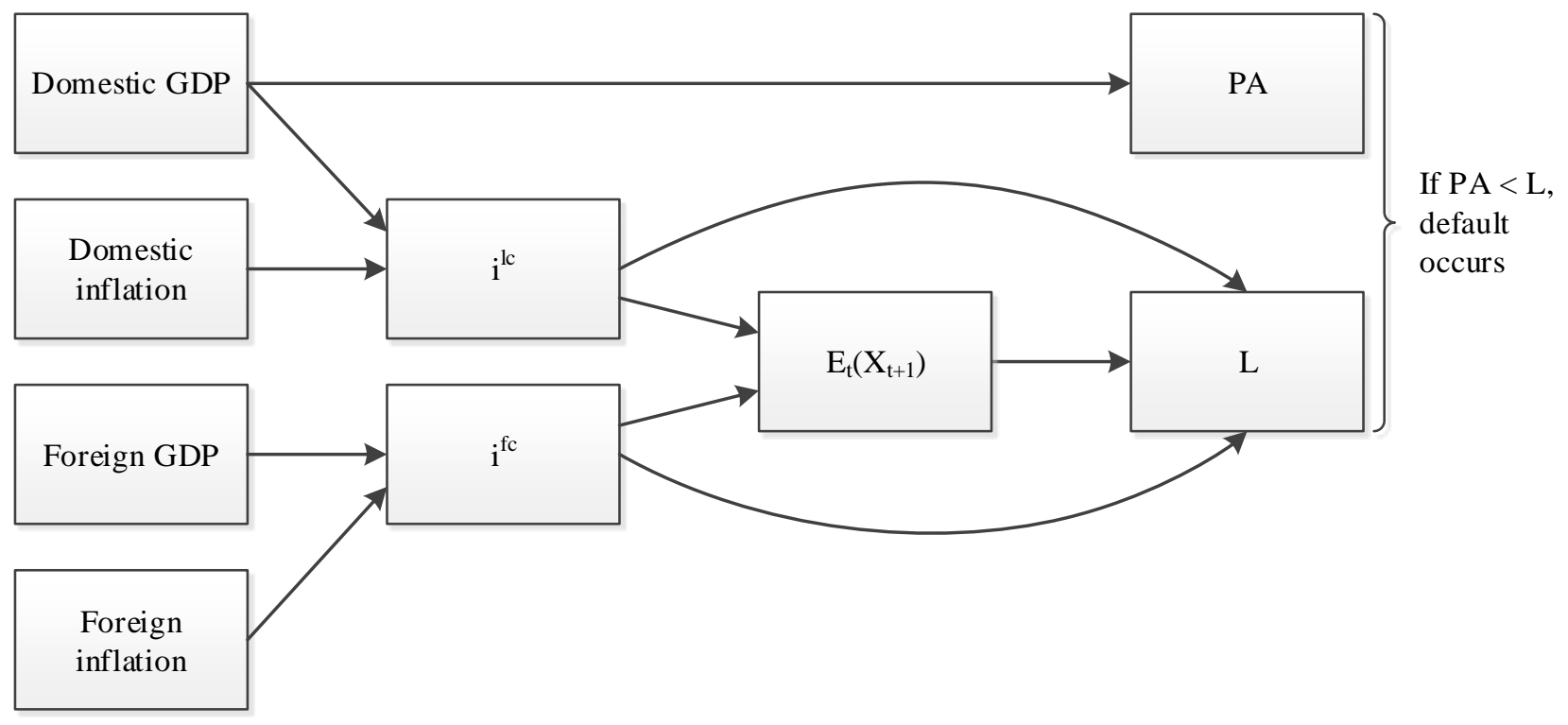

In Taylor (1993), short-term interest rates are assumed to follow the process:

$i_{t}=\pi_{t+4}+r r^{e q}+b\left(\pi_{t+4}-\pi_{t+4}^{t a r}\right)+(1-b)\left(\ln Y_{t}-\ln \bar{Y}_{t}\right)$,

where $\pi_{t+4}$ is the inflation rate projected four quarters ahead, $r r^{e q}$ is the equilibrium level of real interest rate, $\pi_{t+4}^{\text {tar }}$ is targeted inflation one year ahead, $Y_{t}$ is GDP at time $t$ and $\bar{Y}_{t}$ is potential GDP at time $t$, both in real terms. The intuition behind the Taylor monetary policy rule is that central banks react by adjusting policy rates either if inflation is projected to miss the target, or if the output gap is widening. Monetary authorities will increase short-term rates when they foresee the inflation overshooting or when the positive output gap is widening. Conversely, if the inflation projection is 
below targeted level, or if the output gap is negative, central banks will typically respond by relaxing monetary policy in order to stimulate the economy.

Coefficient $b$ in equation (4) determines the relative weight that the central bank assigns to inflation deviating from the target and to output gap, reflecting their view on relative importance of these imbalances. In Taylor (1993), $b$ is set to 0.5. Nevertheless, it is recognised that $b$ can take any value between 0 and 1 . In the extreme case, if $b$ is set equal to one, monetary authorities care exclusively about inflation meeting its target (pure inflation-targeting regime) and do not react to deviations of GDP from its potential level. The more $b$ departs from 1, the greater the importance of GDP gap in monetary policymaking. In the opposite extreme, if $b$ is equal to zero, the central bank is actually targeting potential economic growth and not inflation.

The sum of the first two terms on the right-hand side of equation (4) represent the so-called neutral interest rate, which can be thought of as the nominal equilibrium interest rate. It is the short-term nominal rate that is consistent with the long-term economic growth and price stability. That is, if the inflation is projected to meet the target and the output is at its potential level, the short-term interest rate suggested by the Taylor rule in (4) will be equal to the neutral interest rate.

Following Bergström et al. (2002), we modify the original Taylor monetary policy rule in order to account for the persistence of monetary policy. Intuition behind this modification is the notion that central banks are reluctant to make sharp turns in monetary policy and prefer to adjust policy rates smoothly. This means that monetary authorities will tend to take into account the current level of shortterm interest rates when setting their key policy rates. Hence, in this paper we assume that interest rates follow the process of the form:

$i_{t}=\gamma i_{t-1}+(1-\gamma)\left(\pi_{t+4}+r r^{e q}+b\left(\pi_{t+4}-\pi_{t+4}^{t a r}\right)+(1-b)\left(\ln Y_{t}-\ln \bar{Y}_{t}\right)\right)$

The first term proportional to the lagged interest rate $i_{t-1}$ is the extension that accounts for the persistence of monetary policy. The higher the coefficient $\gamma$, the smoother the changes in short-term rates. Setting $\gamma$ equal to zero leads back to the original Taylor rule (4), while setting it equal to one would suggest flat interest rates, unaffected by either inflation overshooting or the output gap.

Exchange rate expectations are typically revealed through the uncovered interest rate parity (UIRP): 
$\left(1+i_{t}^{l c}\right)=\frac{E_{t}\left(X_{t+1}\right)}{X_{t}}\left(1+i_{t}^{f c}\right)$

where $E_{t}\left(X_{t+1}\right)$ is the risk-neutral expectation of the spot exchange rate at time $t+1$, conditional on the information available at time $t$. In reality, the UIRP does not hold exactly. One way to restore it is to assume that investors require substantial risk premia for holding currencies they deem less safe. Hence, we modify the UIRP as follows:

$\left(1+i_{t}^{l c}\right)=\frac{E_{t}\left(X_{t+1}\right)}{X_{t}}\left(1+i_{t}^{f c}\right)(1+r p)$

where $r p$ is the risk premium for lending in local currency. Rearranging the terms in (7), we obtain the expectation of future spot exchange rate as

$E_{t}\left(X_{t+1}\right)=\frac{\left(1+i_{t}^{l c}\right)}{\left(1+i_{t}^{f c}\right)(1+r p)} X_{t}$

In Section 3, we will use this expectation as a forecasting tool.

\section{Empirical illustration}

To illustrate the model, we use industry-wide data from the Serbian banking sector. Serbian banks shifted almost the entire exchange-rate risk to their borrowers by approving mostly euro-denominated loans. As a consequence, capital requirements for exchange-rate risk account for less than 1 percent of overall Pillar 1 capital requirements. ${ }^{3}$

We estimate the model using quarterly data in order to match the frequency of our GDP time series. Daily data on exchange rate, as well as short-term interest rates, were averaged across quarters. We express the exchange rate between the euro (here, the foreign currency) and the Serbian dinar (the local currency) as the nominal dinar value of one euro. Serbian inflation is measured by annual changes in

\footnotetext{
${ }^{3}$ A non-negligible portion of housing loans in Serbia is linked to the Swiss franc. In principle, a model can be extended to account for more than one foreign currency, but this would further complicate the estimation of UIRP equations. In order to preserve the parsimony of the model, we have assumed that the currency of indexation is always euro. This assumption is not so far-fetched, given that the entire housing portfolio accounts for approximately 15 percent of the banking book.
} 
consumer price index (CPI), whereas inflation in the Eurozone is measured by the changes in Harmonised index of consumer prices (HICP). ${ }^{4}$ We use annual changes in order to be consistent with inflation targets, which are commonly expressed in annual terms. GDP levels for both Serbia and the euro area are expressed in real terms and transformed to logarithm prior to running estimations of auxiliary models. For the short-term interest rates we use three-month interbank rates: Belibor, for Serbian dinar, and Euribor, for euro. Although one can reasonably expect that shorter maturities, such as one or two weeks, to move more closely with the key reference rates, we opted for three-month rates because these are commonly used as a basis in floating-rate loans. Hence, with constant interest margins, changes in value of borrowers' interest-bearing liabilities will directly depend on the changes in these rates. Moreover, the correlations of interest rates are very high across maturities. ${ }^{5}$

In order to disentangle the influence of the exchange rate and interest rates on the value of borrowers' liabilities over one year horizon, we use data on bank loans maturing within one year. The loans were collected from the aggregate banking book of Serbian banking sector. ${ }^{6}$ Loan receivables are decomposed into principal receivables in euro, interest receivables in euro, principal receivables in dinar, and interest receivables in dinar.

We start by estimating the coefficients in four auxiliary ARIMA models for GDP and inflation in Serbia and the Eurozone. All auxiliary models have the following general form:

$$
\text { MacroVariable }_{t}=c+\sum_{i} A_{i} \text { MacroVariable }_{t-i}+\sum_{j} M A_{j} \varepsilon_{t-j}+\varepsilon_{t}
$$

Coefficient estimates are shown in Table 1. Note that only the statistically significant AR and MA coefficients are reported.

\footnotetext{
${ }^{4} \mathrm{HICP}$ is a consumer price index which is compiled according to a methodology that has been harmonized across EU countries. The eurozone HICP is a weighted average of price indices of all member states that have adopted the euro as their legal tender.

${ }^{5}$ For instance, correlation of $2 \mathrm{~W}$ and $3 \mathrm{M}$ Euribor is 0.99.

${ }^{6}$ The data were obtained from the National Bank of Serbia for the sole purpose of this research. They refer to the state of the aggregate banking book as of September 2012.
} 
Table 1. Coefficient estimates for auxiliary ARIMA processes

\begin{tabular}{lcccrr}
\hline \hline & $c$ & \multicolumn{2}{c}{$A R_{i}$} & \multicolumn{1}{c}{$M A_{j}$} \\
\hline$\Delta \ln Y_{t}^{\text {Serbia }}$ & $0.004(0.004)$ & $i=3$ & $0.373(0.179)$ & & - \\
$\pi_{t}^{\text {Serbia }}$ & $-0.000(0.005)$ & $i=4$ & $-0.725(0.149)$ & $j=1$ & $0.464(0.155)$ \\
$\Delta \ln Y_{t}^{\text {Euro area }}$ & $0.001(0.001)$ & $i=3$ & $0.670(0.042)$ & & - \\
$\pi_{t}^{\text {Euro area }}$ & $0.007(0.002)$ & $i=1$ & $0.887(0.081)$ & $j=4$ & $-0.900(0.066)$ \\
& & $i=4$ & $-0.210(0.098)$ & & \\
\hline
\end{tabular}

In Taylor rule in equation (5) there are two coefficients to be estimated, $b$ and $\gamma$. Following Taylor (1993), we set $b$ equal to 0.5, meaning that central banks equally care about inflation and economic growth when deciding on the level of their policy rates. Bearing in mind that reluctance to make sharp changes may vary significantly across central banks, we estimate $\gamma$ empirically. In order to be able to do so, first we simplify equation (5) by defining:

$$
\theta_{t}=\pi_{t+4}+r r^{e q}+0.5\left(\pi_{t+4}-\pi_{t+4}^{t a r}\right)+0.5\left(\ln \mathrm{Y}_{t}-\ln \overline{\mathrm{Y}}_{t}\right)
$$

The right-hand side of (10) is completely exogenous. We obtain the dynamics of inflation and GDP from the auxiliary models, summarised in equation (9). Following Bergström et al. (2002), we model the inflation projection under the assumption of adaptive expectations, by taking the expected inflation four quarters ahead $\pi_{t+4}$ to be equal to the current inflation $\pi_{t}{ }^{7}$ Real equilibrium rates for Serbia and the euro area are calibrated as the average values of respective real rates over the period from Q1 2005 to Q3 2012. ${ }^{8}$ We estimate potential real GDP by using Hodrick-Prescott (HP) filter to isolate the longterm trend of real GDP, where the smoothening constant was set to $\lambda=1,600$.

\footnotetext{
${ }^{7}$ One simple version of adaptive expectations can be algebraically presented as follows: $\pi_{t+4}^{e}=\pi_{t}^{e}+\xi\left(\pi_{t}-\pi_{t}^{e}\right)$, where the left hand side is the current expectation of the inflation one year ahead, $\pi_{t}^{e}$ is the last year's expectation of current inflation and $\pi_{t}$ is actual current inflation. The error-adjustment parameter $\xi$ can be set to be between 0 and 1 . Intuition is that current expectations of future inflation reflect past expectations, corrected with an error-adjustment term, in which current expectations are raised or lowered according to the gap between actual inflation and previous expectations. In a very simplistic version, $\xi$ is set to 1 , which reduces the upper equation to $\pi_{t+4}^{e}=\pi_{t}$.

${ }^{8}$ In this approach, the real equilibrium rate is taken to be $4.8 \%$ for Serbia and $0.24 \%$ for the euro area.
} 
In this way, we treat $\theta_{t}$ as known, and substitute (10) into (5) to obtain:

$i_{t}=\gamma i_{t-1}+(1-\gamma) \theta_{t}$

Rearranging the terms in (11), we obtain an equation in a form suitable for an OLS estimation. By running two independent regressions, we estimate the coefficients $\gamma$ in equations for short-term interest rates in Serbia and the euro area to be 0.799 and 0.860 (both statistically significant). By combining (10) and (11), we obtain two processes of the following general form:

$i_{t}=\gamma i_{t-1}+(1-\gamma)\left(\pi_{t+4}+r r^{e q}+0.5\left(\pi_{t+4}-\pi_{t+4}^{t a r}\right)+0.5\left(\ln \mathrm{Y}_{t}-\ln \overline{\mathrm{Y}}_{t}\right)\right)$

Next, risk premium for holding dinar needs to be estimated from the transformed UIRP equation (8). Taking into account the quarterly frequency, and log-linearizing equation (8), we obtain:

$\frac{E_{t}\left(X_{t+1}\right)}{X_{t}}-1=0.25\left(i_{t}^{l c}-i_{t}^{f c}-r p\right)$

which can be further transformed into the following form suitable for empirical estimation of the risk premium:

$X_{t+1}-0.25\left(i_{t}^{l c}-i_{t}^{f c}\right) X_{t}=\alpha+(1-0.25 r p) X_{t}+\varepsilon_{t}$

In equation (14), dependent variable $Z_{t}$ is defined as:

$Z_{t}=X_{t+1}-0.25\left(i_{t}^{l c}-i_{t}^{f c}\right) X_{t}$

and slope coefficient $\beta=1-0.25 \mathrm{rp}$. In order to ensure that the premium for holding dinar rather than euro will be positive and the process for $X_{t}$ remains stationary, we run a constrained regression with $\alpha=0$ and $\beta<1$. This yields an estimate of risk premium of 65.3 basis points. The error term in regression given by equation (14) has an estimate of standard deviation equal to 3.653 .

Finally, we calibrate the initial payment ability $P A_{0}$ based on the future loss that banking sector can reasonably expect to encounter. Banks can rationally expect to receive the following cash flow at maturity of each loan:

$$
\begin{aligned}
E(C F) & =P A^{*} P(\text { survival })+P A^{*} P(\text { default }) * R R \\
& =P A^{*}(1-P(\text { default }) * L G D)
\end{aligned}
$$


where $P($ survival $)$ is the probability that the loan will be repaid fully, $P($ default $)$ is the probability of average borrower defaulting on her liabilities, $R R$ is the recovery rate and $L G D$ is the loss given default. Banks will tend to require the initial payment ability at a level that sets the expected cash flow equal to the entire amount of loan, including both principal and the accrued interest, i.e. $E(C F)=L_{0}$. Hence, rearranging (16) and substituting $E(C F)$ by $L_{0}$, the initial payment ability will be given by:

$$
P A_{0}=\frac{L_{0}}{1-P(\text { default }) * L G D} .
$$

The numerator in equation (17) can be easily retrieved from our banking book data. The denominator can be obtained from the ratio of newly accrued non-performing loans (NPL) to total new loans approved during the same period. The intuition is that NPL ratio can be thought of as useful approximation of the product of default probability and LGD. From the data, we obtain an estimate of $P A_{0}$ to be around $1.08 L_{0}$.

\section{Estimating risk interaction}

In this section we use the developed framework to obtain the loss distributions, estimate VaR measures and calculate the adverse interaction of credit and market risk in the banking book. We use Monte Carlo simulation to obtain paths for the market and macroeconomic variables four quarters ahead, in order to estimate one-year VaR. The algorithm is described as follows.

First, we simulate the auxiliary ARIMA processes for macroeconomic fundamentals using equation (9). We run a Monte Carlo simulation in order to generate error terms as random draws from four independent standard normal distributions. Next, we feed the ARIMA equations into the modified Taylor rule, given by equation (12). Thus, we obtain the one-year-ahead dynamics of short-term interest rates in Serbia and the euro area. These processes further feed into the risk-adjusted UIRP in equation (14) and drive the dynamics of the exchange rate. The simulation gives a large number of different sample paths for macroeconomic and market variables one year in advance.

Next, we focus on the end of the four-quarter period. For simplicity, we assume that all the loans mature exactly after one year. This assumption could have been relaxed, allowing for more diversified 
maturity structure. However, this would additionally complicate the algorithm and would make no significant improvement in terms of conclusions. Moreover, a rationale for not allowing the defaults before the end of a year is that banks often negotiate loan restructuring with their troubled clients prior to recording a default. We further revaluate the level of liabilities and compare it to the simulated payment ability, obtained from equation (2).

In order to disentangle the influence of individual market variables, we divide total liabilities of borrowers at time $t$ into four constituent parts:

1. Interest payments on euro loans;

2. Principal payments on euro loans;

3. Interest payments on dinar loans;

4. Principal payments on dinar loans.

Interest payments on euro loans are affected by changes in both $3 \mathrm{M}$ Euribor and the euro-dinar exchange rate. Principal payments on euro loans are affected purely by the exchange rate, while interest payments on dinar loans are affected purely by 3M Belibor. Dinar principal amounts remain unaffected by changes in the market variables. In each simulation, we revaluate total liabilities using equation (3).

We then compare $L_{t}$ to $P A_{t}$, for $t$ equal to four quarters ahead, across all simulation paths. In every simulation in which liabilities exceed payment ability, a loss is recorded. In our model, the payment ability of borrowers can be below the level of their liabilities due to one of the following reasons: (i) the payment ability of borrowers has declined as a result of economic downturn and/or a borrowerspecific credit event, equation (2); (ii) the level of liabilities in the local currency have increased as a result of increase in exchange rate and/or interest rates, equation (3); (iii) there is a joint effect of increased liabilities and deterioration of the payment ability as a result of macroeconomic coupling driven by equations (12) and (14). In order to disentangle pure credit risk, pure market risk and the integrated risk in the banking book, we form three separate loss distributions. The first one is the distribution of losses caused purely by deteriorating payment ability, holding the level of liabilities constant in the local currency. The second distribution is formed from losses caused purely by market risk in the banking book. These are the losses caused by increasing liability levels when payment ability remains constant. The third loss distribution is obtained by letting both $P A$ and $L$ vary simultaneously. 
Next, we estimate one-year Value at Risk in the banking book, i.e., pure credit VaR, pure market VaR and integrated VaR, as a quantile of the three loss distributions. Finally, we quantify the adverse risk interaction, as the additional Value at Risk in the banking book above the sum of pure credit and pure market VaR:

Adverse risk interaction $=V a R^{\text {Integrated }}-\left(V a R^{\text {Pure credit }}+\right.$ VaR $\left.{ }^{\text {Pure market }}\right)$

We use 99 and 99.5 percent confidence levels. The results obtained from 100,000 simulations are summarised in Table 2. Integrated $99 \% \mathrm{VaR}$ amounts to 15.8 percent of the combined banking book. It is primarily driven by market $\mathrm{VaR}$, accounting for 12.6 percent of the banking book, whereas the contribution of pure credit risk is far less significant, with 0.8 percent. However, the integrated VaR is greater than the sum of two pure VaR measures, resulting in an adverse risk interaction of 2.5 percent of the total banking book. This is approximately the level of capital that a representative bank from our sample should add on to (allegedly conservative) level obtained from the sum of pure-credit and puremarket VaR, in order to cover its unexpected losses at $99 \%$ confidence level.

Table 2. One-year VaR and the adverse risk interaction (percentage of banking book value)

\begin{tabular}{|c|c|c|}
\hline Confidence level & $99 \%$ & $99.5 \%$ \\
\hline Pure credit VaR & 0.757 & 1.679 \\
\hline Pure market VaR & 12.551 & 13.943 \\
\hline Integrated VaR & 15.766 & 17.380 \\
\hline Adverse risk interaction & 2.459 & 1.758 \\
\hline
\end{tabular}

At $99.5 \%$ confidence level, the contribution of credit risk becomes more pronounced, with about 1.7 percent of the total banking book. Pure-market and integrated VaR also increase, but less in relative terms, thereby slightly reducing the adverse interaction effect to 1.8 percent of the banking book. Therefore, at higher confidence levels, the adverse interaction effect is slightly less underestimated. This result should not be surprising given that, in the model, credit VaR is driven by projected economic growth and a random idiosyncratic component. In our simulations, GDP growth one year 
ahead was projected to be low, but positive. Therefore, a slight increase in the payment ability of borrowers is expected. Consequently, deterioration in payment ability will be mostly driven by its idiosyncratic component, i.e., events that affect individual borrowers. Bearing in mind that idiosyncratic component is assumed to be normally distributed, we can reasonably believe that unexpected credit losses will not be high. In Section 5 we will show how the relative importance of pure-credit and pure-market risk changes once we assume economic downturn, instead of projected modest growth.

In order to calculate confidence bands for our VaR measures, we estimated standard error of each VaR using the formula suggested by Jorion (1996):

$$
\operatorname{se}(\hat{q})=\frac{1}{f(q)} \sqrt{\frac{\alpha(1-\alpha)}{N}}
$$

where $\alpha$ is the confidence level of the VaR estimate, $N$ is the number of observations in the underlying sample and $f(\cdot)$ is the empirical probability density function evaluated at quantile $q$. We estimated the empirical probability densities from the sample loss distributions by kernel density estimation. ${ }^{9} \mathrm{VaR}$ confidence intervals are reported in Table 3. Narrow confidence bounds clearly suggest that our estimates of all VaR metrics in the banking book are sufficiently precise.

Figure 2 displays distributions of unexpected losses originating from pure-credit, pure-market and integrated risk in the banking book, and respective $\mathrm{VaR}$ estimates, together with their confidence bands, as a 99th percentile of loss distributions. Distributions are truncated because no additional gain on top of interest charges can be realised in the banking book. Each time the payment liability of a borrower exceeds her liabilities, she will pay back only up to the amount of principal and accrued interest.

\footnotetext{
${ }^{9}$ Kernel density estimation (KDE) is a non-parametric method for estimating unknown probability density function of a random variable. Kernel density estimation is a fundamental data smoothing problem where inferences about the population are made based on a finite data sample. See, for instance, Parzen (1962) and Rosenblatt (1956).
} 
Table 3. Confidence intervals for $\mathrm{VaR}$ estimates (empirical distribution; $N=100,000 ; 2$ standard-error confidence bounds)

Confidence level

$99 \%$

$99.5 \%$

Pure credit VaR

$[0.755,0.759]$

[1.671, 1.687]

Pure market VaR

[12.456, 12.647]

[13.831, 14.056]

Integrated $\mathrm{VaR}$

[15.652, 15.881]

$[17.245,17.515]$

Figure 2. One-year VaR in the banking book, 99\% confidence level

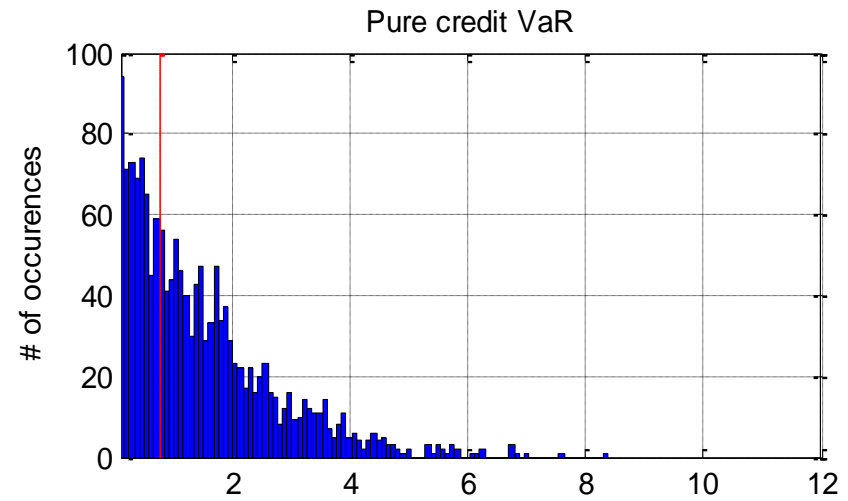

Unexpected loss due to deteriorated PA (\% of banking book)

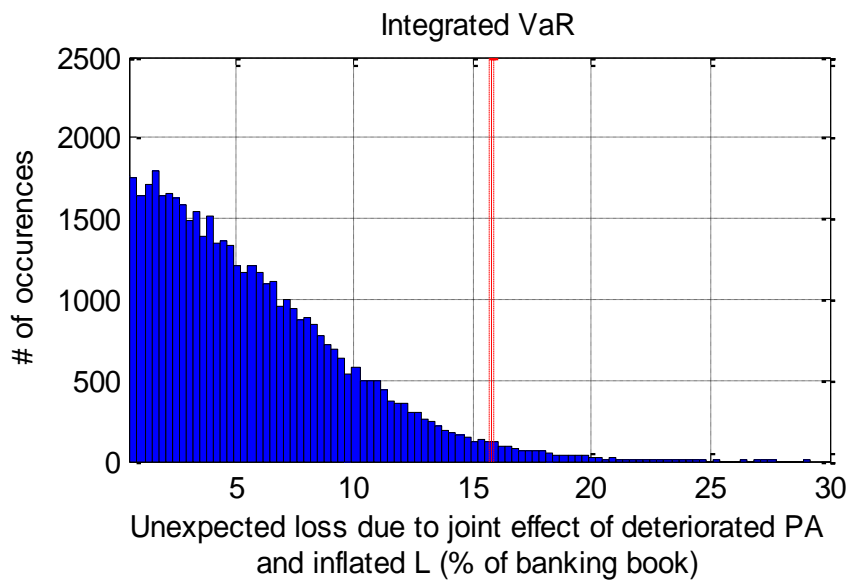

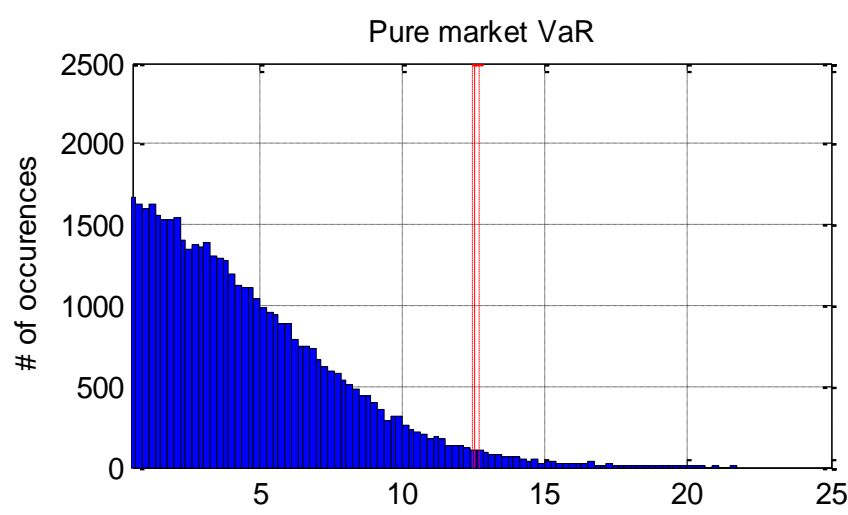

Unexpected loss due to inflated L (\% of banking book)

\begin{tabular}{|l|}
\hline Unexpected loss distribution \\
VaR estimate \\
Confidence bands \\
\hline
\end{tabular}




\section{Applications in risk management}

The integrated VaR measure and quantification of adverse risk interaction can be implemented in risk management procedures. A bank that would implement the proposed model in its risk management framework might opt between two alternatives. One is to use it as a comprehensive tool for the assessment of integrated risk and the other is to focus on the portion of risk arising from adverse interaction of credit and market risk in the banking book.

The first approach refers to using the model as a tool for the assessment of integrated risk in the banking book. Under this approach, capital requirement for integrated risk in the banking book can be obtained as a product of the integrated VaR and a penalty term:

$$
R C^{\text {Integrated }}=p^{*} V a R^{\text {Integrated }}
$$

where $R C^{\text {Integrated }}$ is the regulatory capital charge for integrated risk and $p$ is a penalty term, whose value should be determined based on the results of model back testing. Having obtained integrated risk capital charge, a bank should compare it to Pillar 1 capital charge for credit risk. If the former is greater, Pillar 2 capital add-on for negative interaction of credit and market risk should be a positive difference between the two. If the latter is greater, the add-on should be zero.

The second approach is more modular and can be very practical for banks that want to use the model to estimate capital charge for negative interaction of risks. In analogy with equation (20), capital requirement for the adverse risk interaction can be obtained as a product of the adverse-interaction VaR and a penalty term:

$$
R C^{\text {Adverse risk interaction }}=p^{*} V a R^{\text {Adverse risk interaction }}
$$

In addition to assessment of economic capital, the framework developed in this paper can be readily extended to incorporate macroeconomic stress tests. For instance, in a standard macroeconomic scenario-based stress testing framework, one might think of simultaneous deterioration in economic activity, coupled with an extreme depreciation of the local currency. Using our data, we estimate stressed Value at Risk in the banking book under a scenario involving depreciation of dinar against the euro by 30 percent and a decline in domestic GDP of 10 percent over a one year horizon. Our stress testing procedure applies the same idea as the simulation algorithm from Section 4, the only difference 
refers to the variables being stressed, which are now not simulated, but rather determined based on predefined scenarios. The results of these stress tests are presented in Table 4.

Table 4. One-year VaR at 99\% confidence level under stress scenarios (percentage of banking book value)

\begin{tabular}{lrr}
\hline \hline & Baseline scenario & \multicolumn{2}{c}{ Stress scenario } \\
\hline Pure credit VaR & 0.757 & 4.538 \\
Pure market VaR & 12.551 & 21.886 \\
Integrated VaR & 15.766 & 33.491 \\
& & \\
Adverse risk interaction & $\mathbf{2 . 4 5 9}$ & $\mathbf{7 . 0 6 7}$ \\
\hline
\end{tabular}

As expected, the GDP shock is now severely affecting payment ability, which increases pure-credit VaR roughly by a factor of six, from 0.757 to 4.538 percent. The effect of short-term interest rates being decreased in this scenario is of secondary importance. Therefore, a recession poses risk burden on banks through increased credit $\mathrm{VaR}$ and integrated $\mathrm{VaR}$ in the banking book. Depreciation of the local currency, on the other hand, is inflating the value of borrowers' liabilities, thereby increasing pure-market and integrated VaR in the banking book. The combined effect of these two scenarios is that the adverse risk interaction markedly increases under distressed economic conditions: the sum of two VaR components approximately doubles, but the interaction effect nearly triples.

\section{Conclusion}

This paper examines the interplay between adverse movements of market and credit risk factors. It proposes a framework for quantifying integrated risk arising in the banking book as a result of this adverse interaction. We show how this interaction can be quantified, and illustrate our approach on the example of Serbian banking sector, which is substantially euroized and abundant with non-performing 
loans. We build a Merton-type model based on fundamental macroeconomic relationships. First, we estimate the processes governing interest rates, based on the Taylor rule, modified in order to account for the persistence of the monetary policy. In our model, the expected exchange rate is derived from the uncovered interest rate parity, adjusted to account for risk premium. Next, we simulate the processes for the macroeconomic fundamentals driving the interest rates and the exchange rate, and use the results to calculate the level of borrowers' liabilities one year ahead. We assume that the overall payment ability of borrowers is driven by a systemic component, which appreciates at the same rate as GDP, and an idiosyncratic component, which accounts for borrower-specific events. Each time the payment ability is insufficient to meet the liabilities, a simulation run records a loss. The losses originating from the variations in liabilities and payment ability form the loss distributions, which we use to estimate pure market $\mathrm{VaR}$, pure credit $\mathrm{VaR}$ and integrated $\mathrm{VaR}$ in the banking book. Finally, we estimate the adverse risk interaction, as the additional Value at Risk in the banking book above the simple sum of pure credit VaR and pure market VaR.

We find that the adverse interaction between credit and market risk is positive and amounts to approximately 2.5 percent of the banking book value at 99 percent confidence level. Therefore, we show that, even after accounting for the presence of market risk in the banking book, total risk is still higher than a sum of credit and market risk, thereby imposing the need for integrated approach to risk assessment. Although the integrated risk measure increases with VaR confidence level, the adverse interaction term becomes better captured by the sum of individual market and risk components.

The model can be extended further along several lines. Perhaps the most obvious one refers to the auxiliary processes which govern the dynamics of GDP and inflation. Instead of ARIMA models used in the paper, macroeconomic variables could be modelled endogenously, in a general equilibrium setup. Furthermore, more than a single foreign currency may be incorporated in the analysis. This would make the model a bit more complicated, especially in the part of exchange rate forecasting, as it would bring the need for additional constraints in the optimisation used for assessing the risk premium for holding domestic currency. Nevertheless, it would make the framework more universal.

In our view, the major contribution of this paper is a fairly comprehensive theoretical framework that it provides for an integrated assessment of risks in the banking book. Considering that it is relatively straightforward to implement the proposed model, we hope that the paper may also be of value to practitioners and regulators alike. 


\section{Acknowledgement}

MB acknowledges financial support of Ministry of Education, Science and Technological Development of the Republic of Serbia, grant No. 179005.

\section{References}

Alessandri P. and M. Drehmann (2009), “An economic capital model integrating credit and interest rate risk", Working Paper no 1041, European Central Bank.

Basel Committee on Banking Supervision (2006), "International Convergence of Capital Measurement and Capital Standards: A Revised Framework - Comprehensive Version”. Bank for International Settlements, Basel.

Basel Committee on Banking Supervision (2010), "Basel III: A global regulatory framework for more resilient banks and banking systems". Bank for International Settlements, Basel.

Bergström P., Holmlund A. and S. Lindberg (2002), “The SNDO’s Simulation Model for Government Debt Analysis", Working paper.

Böcker K. and M. Hillebrand (2009), "Interaction of market and credit risk: an analysis of inter-risk correlation and risk aggregation”, The Journal of Risk, Vol. 11/Number 4, pp. 3-29.

Božović M., Urošević B. and B. Živković (2009), "On the spill over of exchange-rate risk into default risk”, Economic Annals, Volume LIV, No. 183.

Breuer T., Jandačka M., Rheinberger K. and M. Summer (2010), “Does adding up of economic capital for market- and credit risk amount to conservative risk assessment?”, Journal of Banking and Finance, Vol. 34(4), pp. 703-712.

Chan-Lau J.A. and A.O. Santos (2006), "Currency Mismatches and Corporate Default Risk: Modeling, Measurement, and Surveillance Applications", Working paper no. 06/269, International Monetary Fund 
Drehman M., S. Sorensen and M. Stringa (2008), "The integrated impact of credit and interest rate risk on banks: an economic value and capital adequacy perspective”, Working paper no. 339, Bank of England.

Jorion P. (1996), "Risk²: Measuring the Risk in Value at Risk", Financial Analysts Journal, 52, pp. 4756.

Merton R. (1974), “On pricing of corporate debt: The risk structure of interest rates", Journal of Finance, Vol. 29, pp. 449-470.

Parzen E. (1962), "On Estimation of a Probability Density Function and Mode". The Annals of Mathematical Statistics, 33 (3), 1065.

Rosenblatt M. (1956), "Remarks on Some Nonparametric Estimates of a Density Function". The Annals of Mathematical Statistics, 27 (3), 832.

Taylor J.B. (1993), "Discretion versus policy rules in practice”, Carnegie-Rochester Conference Series on Public Policy, 39, pp.195-214. 